Please cite as:

Dolnicar, S. (2021) 5/7-point "Likert scales" aren't always the best option: Their validity is undermined by lack of reliability, response style bias, long completion times and limitations to permissible statistical procedures. Annals of Tourism Research, 91: 103297. https://doi.org/10.1016/j.annals.2021.103297

\title{
5/7-POINT “LIKERT SCALES” AREN'T ALWAYS THE BEST OPTION Their validity is undermined by lack of reliability, response style bias, long completion times and limitations to permissible statistical procedures
}

Some research methods are used by default. Even if they undermine the validity of conclusions, authors no longer justify the use of default approaches and reviewers no longer query them. One such default is the use of bipolar ordinal 5/7-point survey answer formats, often incorrectly referred to as 5/7-point "Likert scales". This Viewpoint argues that default answer formats should be replaced by thorough assessments of the benefit-to-cost ratio of alternative answer formats for every survey question asked. Benefits of answer formats include enabling respondents to meaningfully express themselves, while keeping respondent burden low. Costs include reducing data quality by introducing bias or overburdening respondents, or by collecting data at a scale level that limits permissible statistical procedures. The following costs are associated with using bipolar ordinal 5/7-point answer formats:

Low test-retest reliability. Survey respondents do not provide the same response to the same survey question twice, even under unchanged circumstances. On 7-point answer formats, they only do so in $47 \%$ of cases; on 5-point formats in $57 \%$ of cases (Figure 1), suggesting low test-retest reliability in absolute terms, and relative to other formats, such as the forced choice full binary answer format $(82 \%)$.

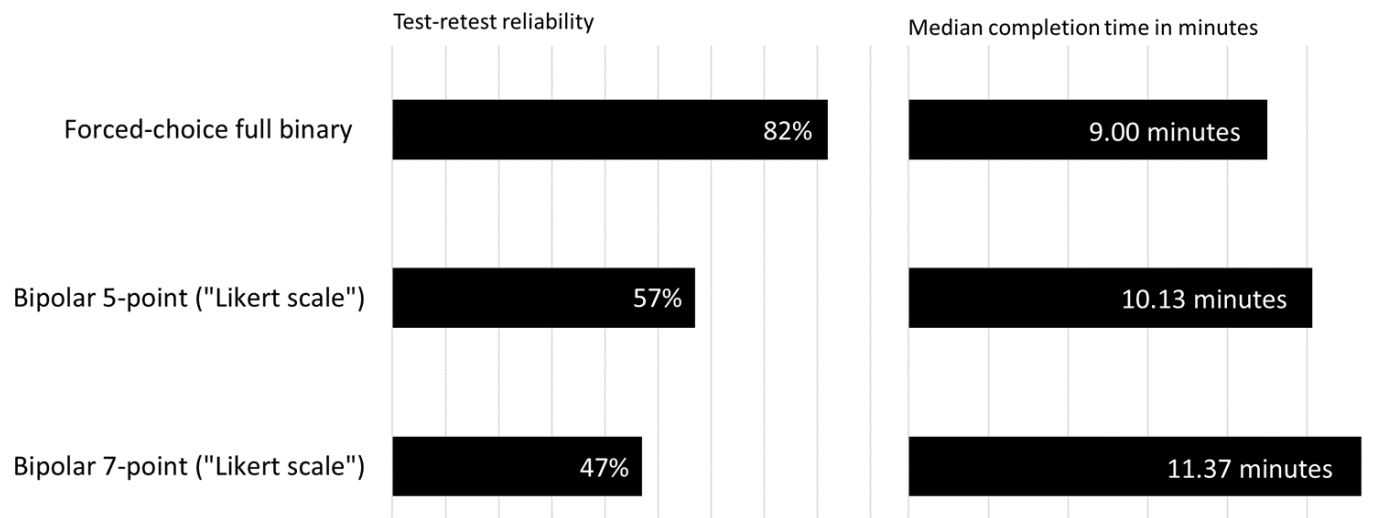

Figure 1. Test-retest reliability (percentage of respondents giving the same response twice under unchanged conditions) and median completion time in the context of image measurement (source: Dolnicar \& Grün, 2013)

Time required to respond. 5/7-point formats take longer to complete than binary formats (Figure 1). Longer surveys produce lower quality data (Johnson, Lehman \& Horne, 1990) and increase survey cost. 
Response styles. Survey respondents have personal preferences for certain answer options, irrespective of the question asked. Such "differences in extremeness between persons ... represent primarily response sets characteristic of the individual" (Peabody, 1962, p.73) rather than differentiated responses to the question content. This means that offering respondents 5/7-point answer options does not generate more refined responses compared to "coarse dichotomous or trichotomous scales" (Matell \& Jacoby, 1971, p. 673), capturing instead response styles, which reduce data quality. Of particular concern in tourism are culture-specific response styles (Triandis \& Triandis, 1962), which make "differences in group means ... uninterpretable" (Chun, Campbell \& Yoo, 1974, p.467).

Statistical limitations. 5/7-point answer formats generate ordinal data, for which "statistics involving means and standard deviations ought not to be used ... for these statistics imply a knowledge of something more than the relative rank-order of data" (Stevens, 1946, p.679). Yet, most tourism researchers rely on reporting mean values or on using them in data analysis (e.g., to test intervention effectiveness in experiments; Viglia \& Dolnicar, 2020). If means are required, it is preferable to collect metric data using answer formats such as slider scales.

Table 1. Sample benefit-cost-analysis for alternative answer formats

\begin{tabular}{|c|c|c|c|c|}
\hline & $\begin{array}{l}\text { Bipolar } 5 / 7 \\
\text { point ordinal }\end{array}$ & $\begin{array}{l}\text { Forced choice } \\
\text { full binary }\end{array}$ & Metric slider & $\begin{array}{l}\text { Another } \\
\text { format }\end{array}$ \\
\hline Example & $\begin{array}{l}\text { Brisbane is safe } \\
\circ \text { Strongly agree } \\
\circ \text { Agree } \\
\circ \text { Neither / Nor } \\
\circ \text { Disagree } \\
\circ \text { Strong disagree }\end{array}$ & $\begin{array}{l}\text { Brisbane is safe } \\
\circ \text { Yes } \\
\circ \text { No }\end{array}$ & $\begin{array}{l}\text { Brisbane is safe } \\
0 \%|------| 100 \%\end{array}$ & \\
\hline $\begin{array}{l}\text { GAIN BENEFIT } \\
\text { Meaningful response options }\end{array}$ & $\begin{array}{l}\text { Depends on } \\
\text { question }\end{array}$ & $\begin{array}{l}\text { Depends on } \\
\text { question }\end{array}$ & $\begin{array}{l}\text { Depends on } \\
\text { question }\end{array}$ & $\begin{array}{l}\text { Depends on } \\
\text { question }\end{array}$ \\
\hline $\begin{array}{l}\text { GAIN BENEFIT } \\
\text { Short completion time }\end{array}$ & $x *$ & $\checkmark *$ & $\begin{array}{l}\text { Unknown, probably } \\
\mathbf{x}\end{array}$ & $\ldots$ \\
\hline $\begin{array}{l}\text { GAIN BENEFIT } \\
\text { Works in online surveys }\end{array}$ & $\checkmark$ & $\checkmark$ & $\checkmark$ & \\
\hline OTHER BENEFITS & $\ldots$ & $\ldots$ & $\ldots$ & $\ldots$ \\
\hline $\begin{array}{l}\text { AVOID COST } \\
\text { High test-retest reliability }\end{array}$ & $x *$ & $\checkmark *$ & $\begin{array}{l}\text { Unknown, probably* } \\
x\end{array}$ & $\ldots$ \\
\hline $\begin{array}{l}\text { AVOID COST } \\
\text { Avoid capturing (cross-cultural) } \\
\text { response styles }\end{array}$ & $x$ & $\begin{array}{l}\checkmark \text { (extreme) } \\
\times \text { (acquiescence) }\end{array}$ & $\begin{array}{l}\text { Unknown, probably } \\
\mathbf{x}\end{array}$ & $\ldots$ \\
\hline $\begin{array}{l}\text { AVOID COST } \\
\text { All statistical procedures permissible }\end{array}$ & $x$ & $x$ & $\checkmark$ & $\ldots$ \\
\hline OTHER COST & $\ldots$ & $\ldots$ & $\ldots$ & $\ldots$ \\
\hline
\end{tabular}

Every methodological choice comes at a cost. The cost of using 5/7-point answer formats is high: they generate unreliable data, capture (cross-cultural) response styles, limit permissible statistical procedures, and take a long time to answer. There may be valid reasons to use 5/7-point answer formats in some instances, but they do not represent a good default answer format. No answer format should be used as a 
default and go unquestioned by authors, reviewers, and readers. Instead, the optimal answer format for each survey question should be determined by carefully assessing the benefit-to-cost ratio of all available alternative answer formats (Dolnicar, 2013). This represents a fundamental departure from the current business-as-usual approach in tourism survey research; one that is critically important to ensure the validity of conclusions drawn.

\section{References}

Chun, K.T., Campbell, J.B., \& Yoo, J.H. (1974). Extreme response style in cross-cultural research Reminder. Journal of Cross-Cultural Psychology, 5(4), 465-480.

Dolnicar, S. (2013). Asking good survey questions. Journal of Travel Research, 52(5), 551-574.

Dolnicar, S., \& Grün, B. (2013). Validly measuring destination image in survey studies. Journal of Travel Research, 52(1), 3-14.

Johnson, M., Lehmann, D., \& Horne, D. (1990). The effects of fatigue on judgments of interproduct similarity." International Journal of Research in Marketing, 7(1), 35-43.

Likert, R. (1932). A technique for the measurement of attitudes. Archives of Psychology, 22(140).

Matell, M.S., \& Jacoby, J. (1971). Is there an optimal number of alternatives for Likert scale items? Educational and Psychological Measurements, 31, 657-674.

Peabody, D. (1962). Two components in bipolar scales: direction and extremeness. Psychological Review, 69(2), 65-73.

Stevens, S.S. (1946). On the theory of scales of measurement. Science, 103(2684), 677-680.

Triandis, H.C., \& Triandis, L.M. (1962). A cross-cultural study of social distance. Psychological Monographs: General and Applied, 76(21), 1.

Viglia, G., \& Dolnicar, S. (2020). A review of experiments in tourism and hospitality. Annals of Tourism Research, 80, 102858. 